\title{
Maître du verre, maître du verbe A propos de trois verreries parlantes d'Emile Gallé
}

\author{
Stephen Foster \\ Old Dominion University
}

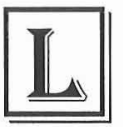

es musées régionaux, qui sont moins exigeants pour nos sens et nos intellects que ces géants des capitales, invitent à la rêverie, à la méditation. Ce sont des refuges, des échappatoires au banal quotidien, amis fidèles des heures grises. Un jour d'incertitude alors que nous errions dans les salles à demi-désertes de notre musée local ${ }^{1}$, notre regard se posa non sur les célèbres Gauguin et Georges de la Tour, mais sur des vitrines semblant sortir de forêts fantasmagoriques et contenant des coupes, des bols, des vases, réceptacles divers à la fois audacieux et intemporels dans leurs formes et dans leurs coloris. Sur leurs rotondités étaient gravés plusieurs vers familiers et un nom : Emile Gallé. Une forte connivence s'établit alors entre le néophyte en l'Art nouveau que nous fûmes, l'artiste qui conçut ces objets et le poète qui les inspira. Nous voulûmes en savoir plus sur l'artiste qui parafait sa signature des messages des anciens bardes, Virgile, Hésiode, Dante, Shakespeare, Villon, et de ceux plus proches de nous, comme Victor Hugo, Baudelaire, Musset, Lamartine, Maeterlinck, Robert de Montesquiou, et bien d'autres. Quel fil d'Ariane avait conduit ce verrier-céramiste, fondateur de l'Ecole de Nancy, féru de botanique et passionné d'orientalisme, de musique et de spiritualisme, vers tous ces magiciens des mots, passant à travers les temps?

Robert de Montesquiou, qui fut l'un de ces génies de la faconde, reconnaîtra en Gallé un de ces pairs et lui consacra un hommage suprême dans son poème intitulé "Galerie " :

1 Le musée Chrysler, qui se trouve à Norfolk en Virginie, est souvent considéré parmi les dix plus insolites musées des Etats-Unis. Son mécène, Walter P. Chrysler, amassa une importante collection de verre rivalisant avec celle du musée Corning (New York). 
Gallé, prince du verre et prêtre du vitrail,

Régent du cristal clair où l'arc-en-ciel s'éploie :

Qui vas pilant du spath et filant du corail

Pour mêler à des mots au creuset qui tournoie.

Bernard Palissy, Benvenuto Cellini

De cette malléable et ductile matière;

Qui nous verses dans l'art de ton vase infini

Comme l'enivrement d'une extase dernière.

[...] Il semble que ce vase aux tons d'iridium

Soit l'œuvre d'Edgar Poe ou bien de Baudelaire².

Ces trois verreries parlantes qui retinrent notre attention dans ce musée particulier illustrent parfaitement les vers de Montesquiou. La première, en verre soufflé parcheminé, couleur d'ambre, émaillée d'une figure de reine, n'était-ce pas " ce rêve en verre " dont l'inconnue qui le traverse nous posait l'éternelle question des "Dames du temps jadis ": Mais où sont les neiges d'antan?

Après François Villon, c'est Maurice Rollinat qui lui inspire un deuxième vase, plus moderne, bariolé de rouge, de bleu et de gris métallisé, traduisant tout à fait l'univers tourmenté de l'auteur de cette complainte : Et maintes fois, plein de langueur, / Le souvenir y monte au Cour / Sa fleur mélancolique et bleue 3 . Le poète des Névroses, aujourd'hui oublié, fut le protégé de George Sand et de Sarah Bernhardt, tour à tour adulé et méprisé par sa génération. Cette Belle Epoque était connue pour ses excès dans tous les domaines, et, en représentant de l'Art nouveau, Gallé avait compris les humeurs changeantes de cet admirateur de Baudelaire et d'Edgar Poe, qui fuyait les tentations du mal dans la nature, la musique, l'art en général. Ce Lorrain, ce grand mystique, semble surtout avoir été influencé par les poètes introspectifs, d'une sensibilité romantique. Alors que verre et cristal sont synonymes de transparence, de pureté, d'éclat, son art est bien ancré dans ces brumeuses marches de l'Est dont il était natif.

Des fleurs, des insectes surgissent de la pénombre, comme ces dahlias et clématis que l'on retrouve sur notre troisième verrerie parlante dédiée à

2 Robert de Montesquiou, "Galerie ", Le Chef des odeurs suaves (Paris, Georges Richard, 1893), pp. 110-111.

3 Ces vers sont tirés d'un poème de Rollinat singulièrement intitulé " La Vase ", La Nature (Paris, Charpentier, 1892), p. 147. 
Marceline Desbordes-Valmore. Le verre n'est plus traversé des fulgurations de couleurs violentes, mais reste sobre, avec de teintes mélancoliques, vert olive et ambre. Il traduit bien la tristesse, la simplicité et la compassion de l'auteur de ce vers: Béni soit le coin sombre où s'isolent nos coeurs ${ }^{4}$.

Gallé expliqua sa connivence avec les poètes dans Ecrits sur l'art à propos d'un vase créé pour Pasteur. Cette fois, c'est Victor Hugo, "l'inspiré par excellence ", selon Claudel, qui le guida dans sa création. Il écrit :

[...] Entre toutes, l'œuvre de Hugo est fertile pour l'artiste. Presque à l'égal des Écritures, ses textes abondent en visions colorées, en verbes lapidaires, en application qui prennent mesure aux statures les plus hautes. Le poète s'exalte à nous peindre les hommes de désir et de sacrifice, les mages, les amants des austères voluptés, ceux qui vont

Recueillant en chemin

La bénédiction de tout le genre humain,

Ceux qui se donnent à la recherche de la vérité et passent songeurs, penchés sur la vie et sur

L'énigme où l'être se dissout ${ }^{5}$.

Il expliquera en outre que le poète, comme l'artiste, est un visionnaire qui peut transcender le néant en voyant :

\section{s'étoiler de rayons}

Le gouffre monstrueux plein d'énormes fumées,

[...] Le verrier avait donc rêvé de jeter au creuset ce grand geste de la science, de faire flotter dans la pâte vitreuse les monstres eux-mêmes, les

4 Nous trouvons ce vers, légèrement changé [... où siisole mon coeur], dans son poème "Les Enfants à la communion ", Bouquets et prières [1843], in Les Oeuvres poétiques de Marceline Desbordes-Valmore, tome 2 (Grenoble, Presses Universitaires de Grenoble, 1973), p. 457.

5 Emile Gallé, "Le Vase Pasteur ", Ecrits pour l'art (Marseille, Laffitte Reprints, 1980), p. 148. Cette coupe en cristal fut offerte à Pasteur par l'École normale supérieure à l'occasion du soixante-dixième anniversaire de sa naissance, et sa déscription figura dans la Revue encyclopédique, numéro du 15 mai 1893. 
fléaux masqués, dépouillant les chimériques lambeaux, les hypothèses fumeuses ou spécieuses que vous avez, Maître, mises à néant.

\section{Elles quittent leur Stymphale sur vos adjurations, Évocateur des atomes! \\ De l'inspiration presque divine de Hugo, ce noir cristal n'est qu'une paraphrase $[\ldots]^{6}$.}

Selon François de Tacon, Hugo sera représenté près de cinquante fois dans l'œuvre du verrier qui fut aussi céramiste et ébéniste?.

L'identité de la personne qui offre, ou à qui l'on a offert, un objet de Gallé constitue un autre lien entre l'artiste et son sacerdoce. Ainsi Marcel Proust offre à Anna de Noaille un vase orné d'une fougère qui est un symbole de la mort dans une de ses nouvelles ${ }^{8}$. Anna le remercie en ces termes dans une lettre datée du 8 janvier 1904 :

Mon cher Marcel,

Il faut que je vous dise encore mon plaisir, mon orgueil de ces chères fougères attendrissantes, sur ce bel herbier de verre. Elles font un dessin sur mon Cœur, le dessin de leurs doux petits corps d'herbages étendues, - et de mon amitié pour vous?.

L'osmose est si complète entre Marcel Proust et Gallé que l'un de ses critiques le compare à ce dernier :

Cet esthète pénétré ne traduit pas ses pensées en prose décadente. Il écrit, quand il médite ou rêve, un français flexible, flottant, enveloppant, en échappements infinis de couleurs et de nuances, mais toujours translucide, et qui fait songer, parfois, aux verreries où Gallé enferme ses lianes. Exact, quand il décrit, ses images,

6 Ibid, pp. 150-151. Les vers que cite Gallé parviennent du poème "A celle qui est restée en France » dans Les Contemplations.

7 François de Tacon, "Hugo dans Gallé ", Centre National de la recherche scientifique / Analyse et traitement informatique de la langue française / Université Nancy II, http://www.inalf.fr/_ie/victorhugo/Galle/Galle/htm.

8 Cette nouvelle, L'Exhortation, avait paru dans La Renaissance latine du 15 novembre 1903.

9 Marcel Proust, Correspondance, tome IV (Paris, Plon, 1978), p. 30. 
comme celles de son maître, procèdent le plus souvent de l'Écriture, qui est somptueuse et précise à la fois ${ }^{10}$.

Les verreries de Gallé, tout comme la madeleine de la Recherche, nous offrirent tout un monde passé et futur en nous ouvrant les portes de la science, l'histoire, la botanique, la littérature, et plus encore. Aux quatre coins de l'univers, des privilégiés comme nous le fûmes, rêvèrent devant " un grillon, une sauterelle déployant l'éventail rose de ses ailes plissées ${ }^{11}$ " et se mirent à répéter la charmante promesse de Shakespeare :

Je le dirai tout bas,

Si bas,

Que le grillon, là-bas,

$\mathrm{Ne}$ l'entendra pas.

— Conte de Noël ${ }^{12}$

ou à méditer les vers de Baudelaire :

Homme, nul n'a sondé le fond de tes abîmes,

O mer, nul ne connaît tes richesses intimes,

Tant vous êtes jaloux de garder vos secrets.

— L'Homme et la $\mathrm{Mer}^{13}$

en admirant une pièce sculptée d'algues, de crabes et de coquilles.

10 Albert Sorel, "Variétés : Pèlerinage de beauté; La Bible d'Amiens, de John Ruskin, traduite et annotée, avec une préface, par Marcel Proust ", Le Temps, 11 juillet 1904, p. 3.

11 Emile Gallé, op. cit., p. 123.

12 Ibid.

13 Ibid., p. 124. 